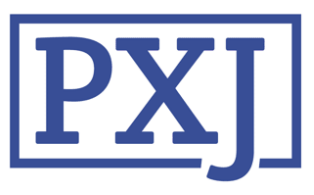

Patient Experience Journal

Volume 1 | Issue 2

Article 16

2014

\title{
Hearing the patient voice: Using video intervention/prevention assessment to understand teens with cystic fibrosis
}

\author{
Susan Horky LSCW \\ University of Florida \\ Laura E. Sherman MSW \\ Wheelock College, Boston, MA \\ Julie Polvinen \\ Boston Children's Hospital \\ Michael Rich MD \\ Harvard University, Boston Children's Hospital
}

Follow this and additional works at: https://pxjournal.org/journal

Part of the Clinical and Medical Social Work Commons, Health Communication Commons, Medicine and Health Commons, and the Pediatrics Commons

\section{Recommended Citation}

Horky S, Sherman LE, Polvinen J, Rich M. Hearing the patient voice: Using video intervention/prevention assessment to understand teens with cystic fibrosis. Patient Experience Journal. 2014; 1(2):104-116. doi: 10.35680/2372-0247.1025.

This Article is brought to you for free and open access by Patient Experience Journal. It has been accepted for inclusion in Patient Experience Journal by an authorized editor of Patient Experience Journal. 


\section{Hearing the patient voice: Using video intervention/prevention assessment to understand teens with cystic fibrosis}

\section{Cover Page Footnote}

This study was funded by the Herbert Bearman Foundation and HRSA Grant \#MCHB T72 MC00002. Many thanks also to the many UF Video Project research assistants who made this project possible.

(https://com-peds-pulmonary.sites.medinfo.ufl.edu/files/2014/10/Research-Assistants.pdf) 


\title{
Hearing the patient voice: Using video intervention/prevention assessment to understand teens with cystic fibrosis \\ Susan Horky, LSCW, University of Florida, chaunst@peds.ufl.edu \\ Laura E. Sherman, MSW, Wheelock College, laurae.sherman@gmail.com \\ Julie Polvinen, Boston Children's Hospital, julie.polvinen@childrens.barvard.edu \\ Michael Rich, MD, Harvard University, Boston Children's Hospital, michael.rich@childrens.harvard.edu
}

\begin{abstract}
This qualitative study asked two questions: 1) How do teens with cystic fibrosis (CF) feel about their treatments; and 2) What factors lead teens to adhere, or not adhere, to treatments. To answer these questions we used an innovative approach (Video Intervention/Prevention Assessment or VIA), to learn about the experiences of teens with CF. We loaned video camcorders to teens with $\mathrm{CF}$ and asked them to create visual narratives of their lives. Researchers logged and coded videotapes, identifying themes that arose from the material. A primary theme was "Doctors don't understand." Participants also highlighted the value of routines and parental support in consistently doing treatments. We identify and discuss themes that emerged and discuss how findings can be used to help providers improve care, develop partnerships with patients and increase adherence.
\end{abstract}

\section{Keywords}

Cystic Fibrosis, chronic illness, video intervention/prevention assessment (via), adherence, patient-centered research, qualitative methods, patient narratives

\section{Note}

This study was funded by the Herbert Bearman Foundation and HRSA Grant \#MCHB T72 MC00002. Many thanks also to the many UF Video Project research assistants who made this project possible. (https://com-pedspulmonary.sites.medinfo.ufl.edu/files/2014/10/Research-Assistants.pdf)

\section{Introduction}

Researchers have long known that strong patient-provider relationships are associated with improved health outcomes and patient satisfaction..$^{1,2}$ Contemporary studies continue to substantiate such findings. ${ }^{3-5}$ In recent years, the concept of Patient and Family Centered Care ${ }^{6-9}$ and the implementation of the Affordable Care Act ${ }^{10,11}$ have shifted the focus even further toward the importance of fully understanding the patient experience. Health care providers must treat and partner with the whole patient and family in order to maintain optimal health.

Cystic Fibrosis (CF) is the most common lethal genetic illness affecting Caucasians. Longevity has increased dramatically over the past 65 years and the median predicted life expectancy is now over 40 years of age. At the same time, however, the patient's treatment burden has risen substantially. To delay the progression of lung disease, people with CF are asked to conduct daily treatments taking two to four hours per day. ${ }^{12,13}$ These include twice-daily airway clearance (often using a vibrating vest to shake the mucus loose in the lungs), multiple nebulized treatments, oral enzymes before eating, and aggressive nutritional plans to gain weight. Many patients, especially adolescents, do not adhere to their CF treatment plans. ${ }^{14-21 .}$ To provide optimal care, health care providers must build strong relationships with patients. Providers must recognize the reasons why teens with $\mathrm{CF}$ sometimes rebel against or neglect their own care by listening to, understanding, and responding to those who live with CF.

"Patients are patients for very little of their illness experience," reminds Kathy Charmaz (p.460). ${ }^{22}$ Patients with chronic illness now live longer than in the past and the vast majority of their care occurs at home. Charmaz explains, "Considerable negotiations occur between patients and practitioners, especially when illnesses become chronic and physicians cannot cure them but instead must rely on patient and family monitoring to manage them medically."'(p.456) Successful health partnerships depend on provider recognition of patients' values, wishes, needs and priorities and subsequent incorporation into the treatment plan. As stated by Rich, "Patients' living situations, behaviors, and life experiences 
have a profound effect on their well-being and their ability to adhere to medical plans. Clinicians may be unable to intervene effectively if they do not understand how patients live with chronic health conditions in their daily physical, psychological, and social environments." (p.156) ${ }^{23}$ Conrad goes even further, asserting, "the major issues in managing long term chronic illness are probably more likely to be social than medical." (p.1257) ${ }^{24}$

One approach to understanding patients' lives calls for a narrative-based medicine in which the patient's illness experience becomes the center of attention. ${ }^{25}$ The physician's task is to successfully listen to the patient and base further treatment on the knowledge gained. Thus far, narrative research on the patient experience of chronic illness has focused on adult patients. ${ }^{26-30}$ Only recently has research started to assess the experience of children with chronic illnesses ${ }^{31-34}$

Children's experiences of chronic illness have generally been studied in clinical settings and relied on self-report, presenting concerns for recall or social desirability bias. In the health care setting, a child or teen presents and is treated as "ill" and, because it is the purpose of the visit, the patients' experience may be focused on their diagnosis rather than the whole of their life experience of illness.

To our knowledge, no studies of $\mathrm{CF}$ adherence have utilized video observations of teens at home and few 15,35 have solicited teen-generated views of adherence/nonadherence. This study used an innovative approach, Video Intervention/Prevention Assessment (VIA), a qualitative method for investigating the experiences of teens with chronic illness. In this study, we loaned video camcorders to teens with $\mathrm{CF}$ and asked them to create visual narratives of their lives. The researcher qualitatively analyzed the video data to explore two research questions: 1) How do teens with CF feel about their treatments; and 2) What factors lead teens to adhere, or not adhere, to treatments. In the following paper we describe the VIA methodology for understanding patients' lives; report our findings on teens' views of CF and CF treatments; provide examples of the ways in which team members used teens' views and feelings to inform their practices; and present general recommendations to help health care providers develop partnerships with patients and increase adherence.

\section{Methodology}

\section{Video Intervention/Prevention Assessment}

The Video Intervention/Prevention Assessment (VIA) methodology was originally developed twenty years ago at Boston Children's Hospital. 23,36 The VIA program has recently expanded to the University of Florida Pediatric Pulmonary Center in Gainesville. With the VIA method, we loan video camcorders to patients and ask them to: "teach us about your life outside of the hospital and what you would like your doctors to know about living with CF." Patients are free to record the aspects of their lives in which they have most interest or feel best conveys who they are. We ask them to talk freely about their condition and this open-ended approach allows them to volunteer the information they feel is most pertinent. Even if phrased in an open-ended manner, survey questions may "lead the witness" simply by the choice of topic. VIA, in contrast, allows a patient to present sides of herself and aspects of her condition that she deems most meaningful. She has full control of the video camera, when she turns it on or off, and what or whom it records.

Video is an immensely powerful medium. The viewer becomes immersed and invested in a patient's life, resulting in an emotional experience that affects the viewer more fully than the cognitive experience of reading or hearing about patient realities. Like the house call, video often conveys information that the participant is not intentionally presenting or of which the participant may be unaware (e.g., presence of other relatives in the home, parental attitude, absence of treatment equipment). ${ }^{36}$ Unlike a clinic visit, video presents an illness experience in context of the patient's life.

As noted by Locatelli et al, ${ }^{37}$ participatory methods of research, such as VIA, "essentially reverse the roles of participant and researcher; rather than the participant entering the researcher's environment to complete the study, the participant invites the researcher into his or her environment, altering the power dynamic."(p.89) VIA is based on the premise that patients are experts on living with illness ${ }^{38}$ and that they have much to teach providers, who are, in turn, the experts on disease. VIA research has found that patients' health outcomes measurably improve simply through the self-reflective act of video recording, before clinicians view their visual illness narratives or change their management. ${ }^{23}$ Patients are given voice and empowered to take ownership of their condition through the VIA method. As a result, their self-efficacy improves. ${ }^{23}$ With increased self-efficacy, patients are more able to care for themselves and adhere to their treatments, leading to improved overall health and quality of life.

This study was part of a larger study which asked additional questions about the lives of teens with $\mathrm{CF}$ and which identified additional themes. Only themes specifically related to CF treatments (in contrast to feelings/themes about having CF generally) were coded. However, the majority of participants' feelings about having CF had to do with treatments. Our research questions were:

1) How do teens with CF feel about their treatments? 2) What factors lead teens with CF to adhere, or not adhere, to their treatments? 


\section{Subjects/Recruitment}

The participants were 19 youth with CF between the ages of 12 and 18 years who attended the University of Florida CF Center. The PI, a clinical social worker and member of the $\mathrm{CF}$ team, explained the project to eligible teens/parents and obtained informed consents and assents. Participants were loaned video cameras and asked to "teach your doctor about your life" by filming everyday events and by talking to the video camera as though it were a diary. Judgment Sampling ${ }^{39}$ was used in which exemplars (representatives of subgroups of the teen population, such as age, gender, family structure, and socioeconomic status) were chosen, based on our knowledge of the population and of CF, in order to assess a diversity of views. Participants recorded approximately 91 hours of participant-generated illness narratives.

\section{Data Analysis}

Participants had full control over the information they chose to share with the research team by returning only the tapes they wanted to be analyzed. Research assistants (termed "loggers") were taught to rigorously "log," a modified form of verbatim transcription that includes not only written explanation of oral content spoken on video, but description of surroundings as well, using Transana ${ }^{40}$ software. Loggers provided objective comments to explicate factual events on the videotapes and also included their own subjective comments (general observations and feelings) to videotapes. Loggers differentiated their subjective responses and interpretive observations from verbatim materials by placing them on separate lines in italics.

After reading the logs, the research team was divided into two subgroups, each developing a list of initial codes to parse out identified themes. Of the codes identified by the first subgroup, $92 \%$ were also identified by the second subgroup. Researchers then coded text into the identified themes using QSR International's NVivo $9^{41}$ software. Text was coded into a given category if a participant explicitly identified a feeling, if the research assistant had indicated that a participant seemed to feel a certain way, or if the coder believed that the text met criteria for the code, based on the flow of narrative or other nonverbal indicators. Loggers' subjective comments were coded into the same categories as participants' comments. Research team members met regularly to discuss category definitions, to decide whether coding categories should be combined or subdivided, and to discuss issues such as researcher bias and deviant samples. ${ }^{39,42}$ Memos documented researchers' thoughts, decisions, and reasoning. Final themes (codes) and definitions are listed in Table 1. Inter-rater reliability was assessed and yielded $83 \%$ reliability. Triangulation (identifying a third way of confirming findings) was further achieved by asking a subgroup of participants whether they agreed with the final conclusions (also known as member checking ${ }^{39}$ ). All participants who were asked concurred with the themes identified.

This study was analyzed using grounded theory. ${ }^{26,38,42}$ Grounded theory has been recommended specifically when doing research with the chronically ill. ${ }^{26}$ Rather than relying on a priori theories for perceiving and categorizing narrative material, we allowed themes to emerge from the material and proposed theoretical constructs based on these themes. The themes identified are listed and defined in Table 1.

\section{Results}

Participants mentioned 36 distinct treatment types throughout the tapes; 223 participant discussions or transcriber observations specifically related to $\mathrm{CF}$ treatments were coded. Themes that emerged are described below, and provide clear and often otherwise unheard insight into patients' lives as they live them with illness. (Note: Names of all participants have been changed to preserve confidentiality.)

\section{How teens with CF feel about treatments}

VIA video illness narratives showed participants voicing a variety of feelings related to their CF treatments.

Oftentimes these feelings would vary from time to time.

Teens with CF shared that they accepted having to do their treatments ('It's just normal"), that they did not like treatment regimens ("It sucks!'), that they felt different just by having to do treatments ('I can't be normal"), and finally, that they wished providers had a better grasp of their experience, of the reality of completing CF treatments ("Doctors don't understand").

\section{"It's just normal"}

Teens frequently communicated acceptance of treatments, describing them as "normal," "routine" or "necessary". Although teens did not pretend to like treatments, they conveyed the sense that these were a fact of life, part of a regular day. In fact, 11 participants voiced their acceptance and habituation to treatment. For example, William, a 16year-old male matter-of-factly scanned the camera over his medications, showing the organized manner in which he stored them. [Link to video: William shows medications http://youtu.be/rcKN-DVZDgE ]. He later stated, "Now treatments, they're, they're okay. They're comfortable, they're not like, you know, painful or anything... it's just something you've got to do." 
Table 1. Treatment and Adherence Themes Identified by Participants

\begin{tabular}{|c|c|c|c|}
\hline \multicolumn{4}{|c|}{ Themes Identified } \\
\hline $\begin{array}{l}\text { Research } \\
\text { Question }\end{array}$ & Theme & Definition & $\begin{array}{l}\text { Number of } \\
\text { Participants }\end{array}$ \\
\hline \multirow{4}{*}{$\begin{array}{l}\text { How do Teens } \\
\text { with CF Feel } \\
\text { About } \\
\text { Treatments? }\end{array}$} & "It's just normal" & Acceptance of and habituation to treatments & 11 \\
\hline & "It sucks" & Dislike of treatments & 11 \\
\hline & "I can't be normal" & Feeling different & 6 \\
\hline & "Doctors don't understand" & Wishing providers understood & 5 \\
\hline \multirow{6}{*}{$\begin{array}{l}\text { What Factors } \\
\text { Lead Teens to } \\
\text { Adhere? }\end{array}$} & "It's just habit" & Value of routine & 11 \\
\hline & "I rely a lot on my parents" & Value of parental and provider support & 8 \\
\hline & "Messing around with..." & Minor treatment modifications & 5 \\
\hline & "I get lots of stuff exempt" & Accommodations due to treatments & 4 \\
\hline & "T've never missed a day" & Preventive beliefs & 7 \\
\hline & "T already explained everything" & Avoidance/Compartmentalization & 4 \\
\hline \multirow{4}{*}{$\begin{array}{l}\text { What Factors } \\
\text { Lead Teens to } \\
\text { not Adhere }\end{array}$} & "He does forget once in a while" & Omitting treatments & 3 \\
\hline & "I don't do my treatments all the time" & Major treatment modifications & 5 \\
\hline & $\begin{array}{l}\text { "If I'm not feeling sick, why do } \\
\text { treatments?" }\end{array}$ & Reactive health beliefs & 3 \\
\hline & No treatments shown or discussed & $\begin{array}{l}\text { Denial; treatments excluded from conscious } \\
\text { thought of participants }\end{array}$ & 4 \\
\hline
\end{tabular}

\section{"It sucks!"}

Teens who seemed to accept treatments at one time often complained about them at another, suggesting their ambivalence. Eleven participants clearly voiced their dislike of treatments, sharing that their biggest concerns were related to the number of treatments, the amount of time spent on treatments, and the intrusion by treatments into their daily activities. Teens found treatments boring and would have preferred to spend time with friends, participate in extracurricular activities or sleep. Participants also lamented the sheer number of pills, inhaled medications and vest treatments they were asked to do. They were equally disturbed by the fact that treatments were never-ending, that teens would need to do these treatments, every day, for the rest of their lives.

William, who had earlier stated his acceptance of treatments, said angrily, at another time, "How do I feel about my medications and treatments? They suck! I take, uuhh whoa about 22, 23 pills a day... with meals... that kind of racks up the number a little bit, and then with treatments that's twice a day and when I'm sick it's four times a day ... that's, to me, that's insane!"

A 12-year-old female, Veronica, explicitly noted that treatments not only take time, but also displace other activities. She declared, "I really don't like CF because I feel like it takes time out of my schedule and my free time. That's getting really irritating... I feel like it takes like time out of my free time..." Parents often agreed about the burden of treatments too. One teen's mom shares, "Yes, it $[\mathrm{CF}]$ affects the family a lot because you have to take breathing treatments; you have to do night feeds." Her son, Brandon, 14, adds, "Which suck." (Turns and points camera to his face).

Sissy (16 year old female) had a more humorous approach, but the sentiments were the same:

Sissy [Interviewing friend): How do you think I feel about doing my treatments?

Friend: You don't want to do them. You want to throw them out a window and kick them down the street. (Sissy laughing in the background) Is that close?

Sissy: Yeah!

\section{"I can't be normal"}

Feeling "normal" is important for teens, including teens with CF. ${ }^{43}$ Participants felt different and embarrassed when others saw their pills, vests or nebulizers, evidence of their treatments. Six participants shared with the camera their concerns about feeling different. Veronica disclosed, "Like, [my friends] and all those people... when I have them over at my house, I feel kinda embarrassed...it's just kinda awkward to show them all my stuff when they don't have that stuff too."

Sean, a 15 year old male, expressed similar discontent: Medications can be annoying sometimes, because a lot of them relating to CF can be like embarrassing... I'm sorry, but if you talked to any other kid who had to use the vest or the treatment, it can be a little embarrassing at times. Just sitting here with this big thing on your face or this big 
thing shaking your chest. It's embarrassing and something I don't like.

William talked about feeling different at school [Link to video: William Embarrassed http://youtu.be/c_N6m0kdoTE].

And the injections! Oh God. Public eye, just feeling stared at. In school, the nurses and stuff, they let me carry my medications. With permission slips obviously, stuff like that. But I could carry it around, and during lunch at school, I would pull out Creon, I would pull out needles and I'd have the whole mobile hospital in my fanny pack... And I would pull this all out and people are just staring like, 'Oh my God...'

\section{"Doctors Don't Understand"}

Whether feeling accepting of treatments, angry with the treatment burden, or feeling as though they are "different," five of the participants also voiced their wishes that providers had a better understanding of the reality of their life with illness. Teens were often complimentary about their health care providers, commenting on how long they had worked with them, and their expertise. However, at times teens expressed frustration at providers' poor understanding of the stress of CF treatments. Sissy lamented, "They don't understand what I do every morning because they don't do it themselves." A similar sentiment was captured in her dialogue below with her mother [Link to video: Sissy-Doctors don't understand http://youtu.be/tzvXsCx6X-U ].

Sissy: No, they [the doctors] care, it's just they don't know...

Mom: They don't understand how much of a routine... Sissy: Routine I have.

Mom: ...it is. Two hours in the morning, two hours at night and then we just started with the insulin, so now it's four sticks a day and four shots a day and...

Sissy: It's just a big routine and they don't understand I have other stuff I gotta get done. If I do have school, I got to get up early in the morning, do meds, do my vest.

Several teens explicitly addressed the providers they envisioned watching the videos, conveying their sense that providers didn't understand. For example, Anna, a 16 year old female, stated, "You doctors and stuff, you probably don't even know what that feels like. Especially you newbies."

William declared vehemently [Link to video: William discussing weight gain http://youtu.be/Cay9wdJ0-1k ].

[Providers say] Hey, you need to gain weight. They show me diagrams and stuff of like 'Here's your level, you should be up here but you're not'... It doesn't bother...It bothers me, 'cause it's kind of annoying... because I know this already. That's what's the annoying part. But it's trying to get there. I actually have to do it. You can say it, and it's just like that saying: 'It's easier said than done'. I have to do it. I have to go home and drink that crappy Boost Plus that they give out to people to gain weight or maintain. That stuff tastes horrible...you should try it!

\section{Factors associated with doing/completing treatments}

Teens with CF expressed a variety of opinions, ideas, and rationales for what influenced their doing/completing treatments. Routine and parental support seemed to be most prominent, voiced by 11 and 8 participants, respectively. Participants also shared how minor treatment modification ("messing around with"), accommodations ("I get lots of stuff exempt"), and compartmentalization ("I already explained everything") were helpful in their completion of treatments.

\section{"It's just babit"”"}

The most common theme related to adherence (both observed and explicitly mentioned by teens) was having a treatment routine. Many participants felt that treatments were just a given. Manny (15 year old male) said, "Um, it's kinda habit now, but I just do the vest, my breathing treatments... um...so it's pretty much second nature now."

In a dialogue with her mother, Katya (12 year old female) is asked:

Mom: ...And [Katya], let me ask you how many days since you were born and at 6 months of age diagnosed with $\mathrm{CF}$, how many days of PT have you missed?

Katya: Zero?

Mom: That's right, you've never missed a day.

Transcripts often showed participants integrating treatments into life, conveying that this was simply the usual order of things. Melissa, a 13 year old female, conveyed in her narrative the natural inclusion of treatments into the stream of her life: "Okay, so right now I just woke up, got my treatment (yawns) and I should go get dressed and everything."

Frequently the participant would say, "Now I have to do my treatment" or a parent might say, "[Teen], its time for your treatment" suggesting that treatments were part of the normal routine.

Treatments were also seen as analogous to chores or other household responsibilities, as in Sissy's response to her mother's question about responsibilities at home. Sissy says "[To] do my [treatment] routine and to do the dishes and have it done."

Transcribers also commented on routines and organization: "[William's] medications are located in what looks 
like a very convenient location for him. His medicines are very organized and this could be a sign of taking medications seriously as far as organization is concerned."

\section{"I rely a lot on my parents"}

The researchers observed that oftentimes, parental support, both emotionally and in creation of routine was crucial to adherence. Eight teens shared on tape that they found it helpful to have parents enforce treatments. William's comment was a tribute to his mother: "My mom is a nurse and I can't tell you how nice that is because you know, she's got skill, you know, where I don't. If she can help me out with scheduling, she's my backbone."

Melissa explained, without apparent rancor, that if she did not maintain her weight, her parents would not allow her to participate in cheerleading. Katya commented, "I rely a lot on my parents (laughs). I will admit it, I do. They really help me."

Parents/caregivers were also frequently observed reminding teens to do their treatments while on video, as in the dialogue below [Link to video: Grandmother reminds Deena http://youtu.be/KtraNj2j4pk ].

Deena: I am going to do my machine now. (Deena goes into the living room and sits down to begin her treatment. She takes a few pumps from her inhaler and then puts on her vest).

Grandma: You doing the machine?

Deena: Yup!

Grandma: Okay girl, have you started?

Deena: No, not yet.

Grandma: Okay, go on then.

\section{"Messing around with"}

Five participants mentioned strategies designed to decrease the treatment burden in small ways. Daniel acknowledged that he didn't do formal airway clearance often, but felt that riding his bike $20-25$ miles per day and playing trumpet had helped keep his lung function super-normal. Katya's parents allowed her to skip her Friday night treatment each week, though she was still required to do her Friday morning treatment. This served as a reward and encouragement to keep going. Manny's mother referred to the occasional flexibility she allowed: "Now last night he didn't want to do it because his stomach hurt. You said, "Can I just do my [breathing] treatments and not the vest?" and I let him slide because he is doing so well now."

\section{"I do get lots of stuff exempt"}

Some teens talked about having fewer household or school responsibilities because they spent so much time doing treatments. Kayla, one of 4 participants who voiced this kind of accommodation said, "Well um, I don't have a ton of responsibilities because I do my therapy every night and morning. It's kind of a pain to do, so they kinda let me have a break with it because it takes an hour a day just to do everything...even longer than an hour."

Accommodations were typically made for schoolwork and household chores. William acknowledged, "You know, it's not like I'm [a] perfect pro here, I mean I do get lots of stuff exempt and lots of stuff [in school is] given more time than most students."

\section{"Never Missed One Day"}

Seven participants shared that their beliefs in prevention motivated them to do their treatments. Kayla maintained, "I think my health is very good. Um, I've done all my treatments...my therapy, hypertonic, Tobi [Tobramycin, an antibiotic], all my pills, everything. I've done it. Never missed one day of doing my therapy, not one day. So, my health is very good..."

Anna said " $[1]$ did some jump-roping and stuff last night, trying to shake it [mucus] out manually. I believe in...you treat your disease [rather] than let it overpower you."

\section{"I already explained everything"}

Several teens (4 out of 12) who had shown and discussed treatments early in their videos, and appeared to do them regularly, were reluctant to discuss CF with others around. For example, the following interchange occurred between Veronica and a friend:

Friend: ... Say some other stuff about CF.

Veronica: I already explained everything I do.

This avoidance was frequently captured in researcher comments:

"I think it is interesting how [friend] tried to prompt Daniel to start talking about his illness a little bit more, but Daniel still focuses on the music." Another researcher shares, "I wonder why she [Kayla] made us watch this instead of addressing serious issues about her health. She seems to avoid her health problems." In all these cases, teens appeared to do their treatments regularly, but preferred not to talk about them in public.

\section{Factors working against doing treatments}

Despite voicing factors that assisted teens in doing treatments, they often shared factors that were barriers to treatment adherence. Three participants discuss omitting treatments, five teens discuss making major treatment modifications on their own, and three voiced reactive health beliefs, specifically, if they felt good, then they could neglect treatments.

\section{"He does forget once in a while"}

Three teens talked about the risk of forgetting treatments, although this was not a widespread concern. Fifteen-yearold Manny's mother commented, "Now he is on inhaled 
Tobi and four Tetracycline pills a day which is kind of hard to do... he does forget one once in a while."

Veronica's friend remonstrated, "Because you always have to do your medicine and if you forget we have to come back all the way back to your house."

\section{"I don't do my treatments all the time"}

Five participants described consciously choosing not to do treatments, thus decreasing the treatment burden in a maladaptive way. Reasons for not doing treatments on a regular basis included that treatments were "a lot" or "too much," not having time, preferring to spend time with friends, and getting out of the routine. Brandon described that he was customarily given a week off from treatments after being discharged from the hospital "because of all I've been through in the hospital." He acknowledged that taking time off made it difficult to re-start treatments again and that he often did not start them up.

In an analogous comment, William admitted, "In fact, I don't do that [my treatments] all the time...I try, I honestly do. But it's just a lot." He later added, "I'll leave a doctor's appointment and be immediately going home for the first week... and go nuts. But then... I'm like oh I can't do it anymore I'm done and that's the point where I'm like, ok I'll take a break."

Loggers also noted the periodic absence of treatments, as in the case where one logger commented, "Deena is eating cheese doodles without taking pills."

\section{"If I'm not feeling sick, why do treatments?"}

Three teens believed that if they felt healthy, they did not need to do treatments. Daniel felt that he was "healthier than most" and did not need to do airway clearance. Reactive/Passive approaches also stemmed from teens feeling that they had little control over their health, and questioning whether preventive care worked.

Sean lamented, "In the end, I know that I have a very restricted amount of health I can control." William echoes Sean saying, "And there's nothing I can do about it. It's just there. And that pisses me off...I can complain about it but it's still going to be there. There's nothing I can do."

Later, he argued, "When I think of a treatment I think of somebody who's sick doing it. So I think if I feel good right now ... why do a treatment you know? ...I'd rather wait till I'm sick...not when I'm healthy."

\section{No treatments shown or discussed}

Four participants did not discuss CF treatments on any of their videos. These participants routinely filmed themselves eating without having taken enzymes and showed homes where no treatment equipment was evident. These participants, perceived by the treatment team to be less adherent, had lower lung function and poorer weight. They seemed to cope by excluding considerations of treatment from their awareness. Clinically, these were individuals whose parents had not developed treatment routines and who appeared to feel that they had little control over their illness.

\section{Discussion}

\section{Implications}

This study identified themes related to: 1) how teens with CF feel about their treatments; 2) factors that lead teens to adhere to treatments; and 3) factors that lead teens not to adhere to treatments. A main finding was that, despite team members' best efforts, teens do not feel that providers understand them or their feelings about treatments. Studies have shown that feeling misunderstood may be a significant cause for non-adherence. In fact, clinician efforts to implement behavioral or other approaches associated with adherence may exacerbate non-adherence if clinicians do not demonstrate authentic understanding of the hardship caused by treatments. ${ }^{44-46}$ The more providers understand the specific feelings of their teen patients, the more they will be able to empathize with them. Explicit understanding of the illness experience and increased empathy from the clinician build a stronger, more trusting relationship, better adherence and improved health outcomes.

Teens find treatments inordinately burdensome and want providers to understand this. Providers may acknowledge that treatments detract from teens' available time and feelings of normalcy, ${ }^{14,19}$ but such acknowledgement is experienced as providing only lip service. Teens want providers to see that CF disrupts their friendships, their sleep, their schoolwork, and their hobbies.

At the same time, teens have intricate and complex feelings about treatments that parallel the complexity of their lives. Teens both accept and resent their CF, their treatments, and their providers, at different times. Teens rarely feel just one way or another, and seldom completely omit, or always perform, their treatments. In addition, grumbling about treatments is to be expected and does not necessarily mean that the teen is not doing his or her treatment routine. Negative comments made in one clinic visit may not reflect the totality of how a teen feels. Teens want providers to truly "get" their feelings, and understand that their feelings are not uni-dimensional.

No adolescent wants to be seen as different from peers. Those with CF prefer to be treated first and foremost as typical adolescents and to discuss their hobbies, activities, and other non-CF aspects of life. Consistent with the findings of Williams et al. ${ }^{43}$, teens want to feel normal internally, as well as being viewed this way by peers. They want to be helped to feel that they are not "CF-ers" but complex individuals, of whom one component is their CF. 
It is therefore important for providers to know details about patients non-CF activities or interests, in order to generate a better connection with the teen to help them understand the importance of treatments and thereby increase adherence.

Another compelling finding in the videotapes, infrequently addressed in other studies ${ }^{35}$ was the role of routine in adherence. Teens appear most likely to adhere if treatments have been part of a consistent routine. Participants occasionally discussed this explicitly, but this was especially visible when simply witnessing family routines. In spite of their complaining, teens of any age also rely on, and appreciate, parental and provider oversight and support in maintaining their treatment routines.

Consistent with other research, we found that health beliefs play a role in patients' adherence behavior. Preventive beliefs, including the belief that teens can influence the course of their illnesses ${ }^{15,21}$ are important in helping teens continue to do treatments. Non-adherence often reflects the opposite belief, a type of "what's the point" feeling that teens can't affect their health trajectory. Non-adherence may be "volitional", 47 reflecting a conscious choice (having weighed the pros and cons) not to do treatments, or it may reflect a defensive rationale for not doing treatments simply because patients dislike them. Consistent with the observations of previous researchers, ${ }^{15,45}$ adherence was generally not "all or nothing", but varied over time, within and between treatments.

In contrast to adults, ${ }^{14}$ forgetting treatments was a relatively infrequent for the adolescents in this study. Teens in families with routines and parental oversight did not forget often; teens in families without routine or parental oversight may not have recognized that they had "forgotten" treatments.

The impact of treatment modification appears to be one of degree. Families who modified treatment routines in minor ways were those adherent most of the time. For this group, treatment modifications (a day or night off) enabled the teens to continue with treatments in a consistent way while also improving quality of life. Families who modified treatments in major ways (skipping many or all treatments) had teens that were sicker overall. Families who generally appeared to cope well (who were organized, thoughtful, less impulsive) used minor modifications, while families with less adaptive coping made major modifications. Poorly coping families seemed less able to make an occasional exception while maintaining the general structure of doing treatments.

We found, as have others, ${ }^{48}$ that "avoidance" (not wanting to talk about CF or treatments in public) can be a positive coping style and is associated with adherence. This is also consistent with Myra Bluebond-Langner's ${ }^{49}$ identification of "compartmentalization" and "avoidance of CF and reminders of its consequences" as coping styles. Families who use this coping style do their treatments and attend to health-related needs. However, they then tend to "file away" issues related to CF and to try to live life as "normally" as possible. This is different from "denial" which occurs when families unconsciously screen CF entirely out of their minds and do not adhere to treatment plans. Denial often indicates a very strong underlying fear of the issue against which the patient is defending. Patients using denial usually have an intense (albeit unconscious) fear of having the full impact of understanding break through in an overwhelming way.

In general, our findings were similar to those of George et al. ${ }^{35}$ who conducted interviews about treatment compliance with older adolescents and adults. Her study identified the burden of treatment, presence or absence of perceived health benefits, forgetting, support and reminders, habits/routines, and stigma (among others) as factors affecting self-management. The fact that we reached similar findings supports the value of qualitative research and learning directly from patients.

\section{Use of VIA to improve care}

The finding that teens with CF do not feel understood by providers affirms the value of using video to educate team members about the specific needs and feelings of individual participants. In the current era of hurried and hectic health care, providers have little time during clinical visits to investigate deeply patients' various feelings, activities or beliefs about their care. Video clips can communicate this information quickly and convincingly.

Excerpts of these video data have been shown to CF team members with compelling results. Video clips

demonstrate, in specific and detailed ways, the impact treatments have on the lives of each individual participant; this has helped providers more fully understand the brunt of treatments. Providers who viewed the videos expressed more compassion and were less judgmental about these patients, discussing them in team meetings with more empathy and conveying greater understanding of patient struggles. One physician developed a more compassionate relationship with Katya after seeing how she meticulously does all her treatments, one after the other, all alone. Another physician was willing to compromise on Veronica's treatments after learning that she had less time to sleep because she stayed up to do treatments after a full day of extracurricular activities. When the physician learned that most of Veronica's activities involved aerobic exercise, he agreed to eliminate one airway clearance treatment daily. Providers seem to have an increased sense of connection with patients simply from having more exposure to, and familiarity with, patients' lives outside of 
the hospital. Using VIA to see the illness experience in the context of a young person's life provides a window otherwise unattainable in a clinic visit. It is a privilege to witness a willing patient's private life. It has the power to humanize medical management and treatment of disease.

Video also provides insight into family dynamics and other life circumstances that influence treatment adherence. From the videos, the team learned about socio-economic situations, family relationships, individual and collective coping styles, and overall tenor of participants' home lives. These insights provide context for treatment issues, as well as allowing the team to feel more connected to the participants.

Due to time limitations, it was often necessary for the PI to summarize findings from a video to providers. The PI was also the team social worker, helping members understand and work with patients was an integral part of her role. A summary, without pictures, sound, context, tone and actions, has significantly less visceral impact than the patient video. Nonetheless, information the PI summarized was often useful for team members. Summaries provided clues on areas of individual interest or concern that clinicians might discuss with patients. For example, Melissa disliked having to babysit for her younger siblings, William's social life primarily involved playing online video games, and David's bedroom was set up according to a movie theme. Daniel, who was reserved in clinic, composed music. [Link to video: Daniel composing music http://youtu.be/z19Eo1ErzvE ]. These types of information allowed team members to engage with aspects of the adolescent that he or she had presented as important, rather than the provider-centered focus on CF.

Providers also benefited from learning about teens' interests, so that they could focus on these as immediate incentives for teens to stay healthy. The PI explained that William was focused on passing the physical test for law enforcement and suggested that this would more likely motivate him to do his vest treatments than a generic concern about "his health", an admonition that he just "should" do his vest, or abstract discussions about extending his life expectancy. Similarly, the PI explained to the respiratory therapist that Kayla liked going shopping with friends and suggested that the respiratory therapist mention to Kayla that with good lung function she would have more stamina at the mall. She suggested to the dietitian that she talk to Randy about the need for extra calories because he was so good at skateboarding and that the physician talk to Tammy about the potential value of a g-tube in helping her win her softball games. Providers began to appreciate the value of connecting with teens in areas unrelated to health. They found that demonstrating their awareness that teens are three-dimensional and have a wide range of school and home-based activities had a positive impact on the doctor-patient relationship. This care dynamic increased teens' trust and willingness to listen to providers and contributed to improved adherence.

The PI was also able to use information gleaned from the tapes to advise team members how to proceed with participants. Based on the finding that many teens hold conflicting feelings, the PI encouraged the physician to give William credit for having mature views some of the time, while also understanding that he lapsed into frustration and youthful attitudes at other times. This vacillation between adult and more childish views is a hallmark of adolescent development. If the physician had responded to William's negative comments about treatments as though they were permanent or universal, it is likely that the conversation would develop into a polarizing "tug-of-war," William would feel misunderstood and trust would be lost. When the physician sat with William's negative feelings prior to conversing with him, she later learned that William had absorbed and considered everything she had said.

Synopses of the videotapes were especially helpful in correcting team assumptions about families or amending team projections about participants' home lives and behaviors. Several participants, who the team had labeled categorically non-adherent, consistently recorded some, if not all, treatments. Team members were surprised to learn that William scrupulously washed and cared for his own nebulizer equipment and that his room and medications were well organized. This factual record ran contrary to their assumptions about him. Daniel, who the team believed "did nothing" in terms of self-care, revealed that he exercised extensively. As the PI provided the essence of the tapes to the team, clinicians obtained a fuller picture of the participants. With more complete and dimensioned understanding of patients, providers are better able to partner with patients to provide optimal health care, and teen patients felt more heard and more supported in the treatment of their illness.

\section{Limitations}

This study had a relatively small population and was conducted in just one clinic, with just one illness. These factors limit the generalizability of this study, so one cannot say that other teens with CF or teens with other chronic medical conditions would have the same feelings. Four potential participants declined to join the project, so this may have led to selection bias. There were many diverse variables (health status, socio-economic status, one/two parent families, siblings with or without CF, educational level) that were not controlled for. Participants had full control of when they turned the camera on and off. Thus, researchers only saw the pieces of information that the patients wanted to share. While less objective, 
however, the subjectivity allowed patients to focus their clinical teams on the issues most important to them.

In addition, teens may have wished to appear exemplary to the camera. However, some talked openly about their distress and non-adherence and four did not mention CF treatments at all, suggesting that this was infrequently the case. As the PI is a member of the CF team, it is possible that prior knowledge of CF or the participants influenced her reading of the transcripts and code development. We hope to have minimized this as much as possible by selfreflection, team discussions, and triangulation.

\section{Conclusions and Recommendations}

Patients have both accepting and rejecting feelings about CF treatments. They may not feel that providers understand their experiences. Parental support, the development of a regular treatment routine, and preventive health beliefs are strongly related to adherence. Major treatment modifications, reactive health beliefs, and total exclusion of treatments from consciousness contributed to non-adherence. VIA is an effective and important way to learn about teens' real lives and feelings. VIA can help the care team develop a better understanding of teens' experiences, build stronger relationships with teens, and improve patient adherence to treatment regimens. Video can provide a more detailed insight into the times and circumstances under which teens do, or do not do, their treatments. This stands in stark contrast to the dichotomous "she does/he doesn't" [do treatments] view often perceived during a hectic clinic. Based on our findings, we make the following recommendations to providers:

1. Team members should convey empathy related to treatment burden. While providers view treatments as "needing to be done," consistently doing treatments is a huge accomplishment for any teen. It will be beneficial for providers to praise teens frequently for doing treatments, indicating that this was above and beyond what is expected, rather than simply assuming that doing treatments is a given. ${ }^{20}$ The more those providers understand the specific feelings of their patients, the more they will be able to empathize with teens. With increased empathy comes a stronger, more trusting relationship, better adherence, and improved health outcomes. ${ }^{50-52}$

2. Team members should consider carefully the degree to which they think the tradeoff between multiple treatments and a patients' quality of life is worthwhile. Based on the VIA videos, there is even a question of whether a full resolution between wishes of providers (the experts on disease) and the needs of patients (the experts on illness) is even possible. Team members should compromise with teens and strive for "realistic" rather than "perfect" treatment regimens. While some providers are reluctant to do this, the process of contemplating this question will at least call them to recognize the degree to which treatments interfere with their patients' lives.

3. Given adolescents' wishes to feel "normal" and their difficulty projecting into the future, providers may want to show interest in the non-CF aspects of teens' lives. Video clips allow providers access to learn about the specific activities that teens enjoy; discussion of these strengthens the treatment relationship. Providers should emphasize that doing treatments will allow teens to participate in activities they enjoy, rather than focusing on physiological or long-term benefits of doing treatments. Providers should partner in care and help teens strategize ways to balance treatments and life activities ${ }^{19}$ and find ways to compromise, identifying the minimum necessary treatment regimen.

4. Team members are encouraged to listen empathetically, rather than critically jumping in when teens complain about treatments, remembering that complaints do not necessarily indicate that the teen is not doing them. When parents mention that teens are resisting treatments, the provider should clarify whether the teen is griping about treatments or actually refusing to do them.

5. Providers should emphasize to parents the importance of getting into a treatment routine as early as diagnosis. Families who develop CF routines when their children are young are more likely to have teens who adhere. With older children, the team can help parents develop routines and organizational skills as a way of supporting adherence.

6. Providers should listen carefully as teens talk, to understand the roots of non-adherence. They should assess the degrees to which non-adherence relates to treatment burden, a wish to be normal, a desire for more time for enjoyable activities, reactive health beliefs, or a sense of futility. Providers must discern whether a teen has thought through her choices, or is impulsively disregarding possible outcomes.

Providers should first simply listen and empathize. They can then focus on teens' specific beliefs as an inroad to discussing adherence issues. Providers can respectfully address the specific sources of nonadherence with the patient through focused health education, thoughtful conversation, and compromise. In working both with adherent and non-adherent teens, providers will find it helpful to explicitly buttress teens' sense of control ${ }^{21}$ and self-efficacy, helping them believe that they can impact their own health.

7. Team members should monitor and provide positive consequences for adherence, even for older teens. Sometimes parents feel teens "should be old enough" to monitor their treatments on their own, but providers should encourage parents to continue to provide oversight and support. Providers may need to 
give teens shorter, more frequent appointments, so they do not lose momentum in consistency with treatments or weight gain efforts.

8. Clinicians should use their clinical judgment in determining how well a family can manage modifications. Team members can help families with strong coping mechanisms maintain adherence by supporting some flexibility. Conversely, providers should help families with poorer coping skills consider consequences and develop treatment routines and structure.

9. Providers can help teens who may forget treatments by suggesting strategies such as alarms, text reminder apps, or placing treatment items in an easily visible location.

10. It is important that providers distinguish the adaptive approach of "compartmentalization" or "avoidance" from "denial". Team members should remember that if a teen is in good health and appears to be doing treatments, providers should support avoidance and compartmentalization, such as by not forcing the teen to talk about CF, but instead focusing on the teen's other life experiences. Denial reflects an intense fear of the topic being denied, so providers should tread gently when working with families who use denial as a coping mechanism and gradually help such patients and families think about the short and long-term consequences of not doing treatments. Providers should simultaneously help these families see that they do have some control over outcomes.

11. Researchers should continue to use VIA to become as familiar as possible with the lives of teens with chronic illness. Teams may want to consider having providers themselves participate in a truncated version of VIA, to bring them closer to the patient experience through on-camera self-expression and reflection. Providers would understand how difficult and courageous it is to open up and share one's life on camera in an effort to become better partners in their own health care. This process would level the playing field between patient and provider, highlight the differences between patients' home cultures and the culture of health care, and promote best practices. Further research should also focus on finding ways to shorten treatments and to identify the minimum treatments necessary for maximum efficacy.

Adolescents in this study did not feel understood by their providers. It is important for providers to better grasp teens' experiences in order to improve patient satisfaction and adherence. This paper has identified particularly salient themes for teens, as well as discussing the value of using patient-created video to better understand teens' lives.

\section{References}

1. Hall JA, Roter DL, Katz NR. Meta-analysis of correlates of provider behavior in medical encounters. Med Care. 1988 Jul;26(7):657-75.

2. Stewart MA. Effective physician-patient communication and health outcomes: a review. Can Med Assoc J. 1995; 152(9): 1423-1433.

3. Brion J. The Patient-Provider Relationship as Experienced by a Diverse Sample of Highly Adherent HIV-Infected People. I Assoc Nurses AIDS Care; 25(2): 123-134.

4. Ayala J, Howe C, Dumser S, Buzby M, Murphy K. Partnerships With Providers: Reflections From Parents of Children with Type II Diabetes. West J Nurs Res. 2014; 1-16.

5. Trentman TL, Chang Y,. Chien JJ, Rosenfeld DM, Gorlin AW, Seamans DP, Freeman JA, Wilshusen LL. Attributes associated with patient perceived outcome in an academic chronic pain clinic.Pain Practice. 2014; 14(3): 217-222.

6. Wiley J, Westbrook M, Greenfield JR, Day RO, Braightwaite J. Shared decision-making: the perspectives of young adults with type 1 diabetes mellitus. Patient Prefer Adherence. 2014;8: 423-435

7. Implementation Project Advisory Committee Council on Children With Disabilities and Medical Home Care for Children and Youth Across Multiple Systems. Patient- and Family-Centered Care Coordination: A Framework for Integrating Care for Children and Youth Across Multiple Systems. Pediatrics 2014;133 (5);e1451-e1460.

8. Clay A, Parsh B. Patients and family centered care: Not just for kids. Patient Prefer Adherence. 2014; 8:423435

9. King G, Chiarello L. Family-centered care for children with cerebral palsy: conceptual and practical considerations to advance care and practice. J Child Neurol. 2014: 1-9.

10. Barksdale D, Newhouse R, Miller J. The PatientCentered Outcomes Research Institute (PCORI): Information for academic nursing. Nurs Outlook.2014;62:192-200.

11. Hooten D, Zavadsky. The Patient Experience Revolution: The Affordable Care Act's emphasis on patient-centered care will transform our industry. JEMS. 2014: 54-57.

12. Eakin MN, Bilderback A, Boyle MP, Mogayzel PJ, Riekert KA. Longitudinal association between medication adherence and lung health. J Cyst Fibros 2011; 10:258-264.

13. Patterson JM, Budd J, Goetz D, Warwick WJ (1993) Family correlates of a 10-year pulmonary health trend in cystic fibrosis. Pediatrics. 1993; 91:383-389.

14. Dziuban EJ, Saab-Abazeed L, Chaudhry SR, Streetman DS, Nasr SZ. Identifying barriers to treatment adherence and related attitudinal patterns in 
adolescents with cystic fibrosis. Pediatr Pulmonol 2010; 45:450-458.

15. Abbott J, Dodd M, Gee L, Webb, K. Ways of coping with cystic fibrosis: implications for treatment adherence. Disabil Rehabil. 2001; 23(8): 315-324.

16. Masterson TL, Wildman GB, Newberry BH, Omlor GJ. Impact of age and gender on adherence to infection control guidelines and medical regimens in cystic fibrosis. Pediatr Pulmonol. 2011; 46:295-301.

17. Withers AL. Management issues for adolescents with cystic fibrosis. Pulm Med. 2012; 1-10.

18. Gudas LJ, Koocher GP, Wypij D.Perceptions of medical compliance in children and adolescents with cystic fibrosis.J Dev Behav Pediatr. 1991;12(4):236-242.

19. Havermans $T$, DeBoeck K. Cystic fibrosis: a balancing act? J Cyst Fibros 2007; 6(2): 161-162.

20. Kettler LJ, Sawyer SM, Winefield HR, Greville HW. Determinants of adherence in adults with cystic fibrosis. Thorax. 2002;57:459-464.

21. Bucks RS, Hawkins K, Skinner TC, Horn S, Seddone $\mathrm{P}$, Horne R. Adherence to treatment in adolescents with cystic fibrosis: the role of illness perceptions and treatment beliefs. J Pediatr Psychol. 2009; 34(8): 893902

22. Charmaz, K, Oelsen, V. Ethnographic Research in Medical Sociology: Its Foci and Distinctive Contributions. Sociol Method Research. 1997: 25 (4): 452494.

23. Rich M, Lamola S, Gordon J, Chalfen R. Video Intervention/Prevention Assessment: A PatientCentered Methodology for Understanding the Adolescent Illness Experience. J Adolesc Health. 2000; 27: 155-165.

24. Conrad, P. Qualitative Research on Chronic Illness: A Commentary on Method and Conceptual Development. Soc Sci Med. 1990; 30 (11): 1257-1263.

25. Charon, Rita. 2006. Narrative Medicine: Honoring the Stories of Illness. Oxford: Oxford University Press.

26. Charmaz K. Discovering chronic illness: using grounded theory. Soc Sci Med. 1990;30(11):1161-72.

27. Charmaz K. Stories of Suffering: Subjective Tales and Research Narratives .Qual Health Res. 1999; 9: 362.

28. Charmaz K. Stories and Silences: Disclosures and Self in Chronic Illness. Qualitative Inquiry. 2002; 8: 302328.

29. Hopman P, Rijken M. Illness perceptions of cancer patients: relationships with illness characteristics and coping. Psycho-oncology. 2014

30. Gabriel R, Figueiredo D, Jacome C, Cruz J, Marques A. Day-to-day living with severe chronic obstructive pulmonary disease: Towards a family-based approach to the illness impacts .Psychol Health. 2014;29(8):96783.

31. Rich M, Chalfen R. Showing and telling asthma: children teaching physicians with visual narratives. Visual Sociology 1999;14:51-71.
32. Rich M, Patashnick JL, Chalfen R. Visual illness narratives of asthma: explanatory models and healthrelated behavior. American Journal of Health Behavior 2002;26(6):442-53.

33. Rich M, Lamola S, Amory C, Schneider L. Asthma in life context: Video Intervention/Prevention

Assessment (VIA). [Video illustrations online at www.pediatrics.org]. Pediatrics 2000;105(3 Pt 1):46977.

34. Jamieson N, Singh-Grewal D, Hanson C. Craig J, Tong A. Fitzgerald D, Children's Experiences of Cystic Fibrosis: A Systematic Review of Qualitative Studies Pediatrics. 2014;133:e1683-e1697.

35. George M, Rand-Giovannetti D, Eakin MN, Borrelli B, Zettler M, Riekert KA. Perceptions of barriers and facilitators: Self-management decisions by older adolescents and adults with CF. J Cyst Fibro. 2010; 9: 425-432.

36. Rich M, Polvinen J, Patashnick J. Visual narratives of the pediatric illness experience: children communicating with clinicians through video. Child Adolesc Psychiatric Clin N Am 2005; 14: 571-587.

37. Locatelli S, Turcious S, LaVela SL. Veterans' experiences of patient-centered care: Learning from guided tours. Patient Experience Journal. 2014: 1(1); 14.

38. Rich M, Taylor SA, Chalfen R. Illness as a social construct: understanding what asthma means to the patient to better treat the disease. Joint Commission Journal on Quality Improvement 2000;26(5):244-53.

39. Marshall MN. Sampling for qualitative research. Fam Pract 1996; 13(6): 522-525.

40. Woods, D, and Fassnacht, C. (2012). Transana v2.50. http://www.transana.org. Madison, WI: The Board of Regents of the University of Wisconsin System.

41. NVivo qualitative data analysis software; QSR International Pty Ltd. Version 9, 2010.

42. Corbin J, Strauss A. Basics of Qualitative Research: Techniques and Procedures for Developing Grounded Theory.Los Angeles: Sage Publications 2008.

43. Williams B, Corlett, J, Dowel JS, Coyle J, Mukhopadhyay S. I've never not had it so I don't really know what its like not to: nondifference and biographic disruption among children and young people with cystic fibrosis. Qual Health Res. 2009; 19: 1443-1455

44. George M, Rand-Giovannetti D, Eakin MN, Borrelli B, Zettler M, Riekert KA. Perceptions of barriers and facilitators: Self-management decisions by older adolescents and adults with CF. J Cyst Fibro. 2010; 9: 425-432.

45. Lask B. Non-adherence to treatment in cystic fibrosis. J R Soc Med. 1994;87(Suppl 21):25-7.

46. Cruz I, Marciel KK, Quittner AL, Schechter MS. Anxiety and depression in cystic fibrosis. Semin Respir Crit Care Med. 2009;30:569-578. 
47. Koocher GP, McGrath ML, Gudas LJ. Typologies of nonadherence in cystic fibrosis.J Dev Behav Pediatr. 1990; 11(6):353-358.

48. Moise J, Drotar D, Doershuk C, et al. Correlates of psychosocial adjustment among young adults with cystic fibrosis. J Dev Behav Pediatr . 1987;8:141-148.

49. Bluebond-Langner M. In the Shadow of Illness: Parents and Siblings of the Chronically Ill Child. Princeton NJ: Princeton University Press;199

50. White T, Miller J, Smith JL, McMahon WM. Adherence and psychopathology in childrenand adolescents with cystic fibrosis. Eur Child Adolesc Psychiatry. 2009; 18:96-104.

51. Miller VA, Drotar D. Decisionmaking competence and adherence to treatment in adolescents with diabetes.J Pediatr Psychol 2007; 32:178-188.

52. Passero MA, Remor B, Salomon J. Patient-reported compliance with cystic fibrosis therapy. Clin Pediatr (Phila) 1981; 20:264-268. 